\title{
Old or Age Indeterminate High Lateral Myocardial Infarction by ECG Finding
}

National Cancer Institute

\section{Source}

National Cancer Institute. Old or Age Indeterminate High Lateral Myocardial Infarction by

ECG Finding. NCl Thesaurus. Code C102688.

An electrocardiog raphic finding of pathologic $\mathrm{Q}$ waves in leads I and $\mathrm{aVL}$, which is suggestive of myocardial infarction of the high lateral wall of the left ventricle, without evidence of current or ongoing acute infarction. (CDISC) 